A COMPARATIVE STUDY OF SURGICAL TREATMENT VERSUS CONSERVATIVE TREATMENT OF VOCAL CORD NODULES IN TERTIARY CARE HOSPITAL

\title{
Medical Science
}

Dr. Indranil Medical Officer (SUPY), Swasthya Bhawan, Kolkata, West Bengal. *Corresponding Khatua* Author

Dr. Alokendu Bose Senior Resident, R. G. Kar Medical College And Hospital. Kolkata.

Dr. Indranath Kundu Professor And Head Department Of Otorhinolaryngology, R. G. Kar Medical College \& Hospital, Kolkata

Dr. Debarshi Jana

Young Scientist (DST) Institute Of Post-graduate Medical Education And Research, A.j.c. Bose Road, Kolkata-700020, West Bengal, India

\section{ABSTRACT}

Background: Vocal cord nodules are bilateral, benign, and callous like growths of the mid portion of the membranous vocal folds. They are of variable size and characterised histologically by thickening of epithelium with a variable degree of inflammation in the underlying superficial lamina propria ${ }^{1}$. They characteristically produced hoarseness, discomfort and an unstable voice when speaking or singing.

AIMS: Comparison between post treatment (surgical and conservative treatment groups) voice quality of the two groups and post treatment status of nodules in both the groups.

MATERIAL AND METHODS: Outpatient department and Indoor wards of Department of ENT and Head Neck surgery, R. G Kar Medical College. Patients attending ENT OPD of R G Kar Medical College during the Study period were the study population. Sample size was atleast 50 Patients.

RESULT: In group-A, 4(23.5\%) patients were regressing and 13(76.5\%) patients had resolve. In group-B, 4(12.1\%) patients were persisting and $29(87.9 \%)$ patients were regressing. Association of post $\mathrm{Rx} V \mathrm{VN}$ vs. group was statistically significant $(\mathrm{p}<0.001)$.

CONCLUSION: Vocal fold nodule is one of the most frequent benign laryngeal lesions, influencing the quality of life of those affected by them, primarily the vocal production. Despite being a well-established therapy in conjunction with surgery, speech therapy alone may also be effective in treating these lesions.

\section{KEYWORDS}

Surgical Treatment, Conservative Treatment, Vocal Cord Nodules

\section{INTRODUCTION}

Vocal cord nodules are bilateral, benign, and callous like growths of the mid portion of the membranous vocal folds. They are of variable size and characterised histologically by thickening of epithelium with a variable degree of inflammation in the underlying superficial lamina propria ${ }^{1}$. They characteristically produced hoarseness, discomfort and an unstable voice when speaking or singing. The prevalence of nodules causing hoarseness in the general population in upto $23.4 \%$ of children, $0.5 \%$ to $1.3 \%$ of ENT Clinic attendances and $6 \%$ of phoniatric clinic attendance 2 . They can be caused by - Voice abuse (prolong shouting or singing above the individual's own range) but may also caused by infection, allergy, or acid reflux ${ }^{3}$. The definition of - vocal abuse is however subjective, although attempts have been made to define objective deviation ${ }^{4}$. The Diagnosis of nodules is by indirect Laryngoscopy and a Fibre Optic Laryngoscope(FOL). Vocal cord nodules can be surgically removed but may also be treated conservatively with medical and pharmacological treatment of infection, allergy, G.I. reflux, and vocal hygiene advice with voice rest and abuse reduction \& vocal retraining. Surgical removal of the nodules includes exicision of nodules with Micro Surgical Instruments(steel)

Vocal fold nodules (VFNs), are localized, benign, superficial growths on the medial surface of the true vocal folds (TVFs) that are commonly believed to result from phonotrauma. Nodules are bilateral with a classic location at the junction of the anterior and middle third of the vocal fold (ie, the midpoint of the membranous vocal fold). Nodules are most often observed in women aged 20-50 years, but they are also found commonly in children (more frequently in boys than in girls) who are prone to excessive shouting or screaming. ${ }^{6}$ Videostrobolaryngoscopy can be used to detect laryngeal lesions. Treatment options for VFNs and vocal fold polyps (VFPs) include invasive and noninvasive techniques, ${ }^{7}$ although surgery for VFNs is rare (fewer than $5 \%$ of cases).

In this patient with hoarseness, opposing nodules are clearly seen at the anterior one third of the true vocal cords. These responded nicely to outpatient nonsurgical treatment (voice therapy).

Confronted with symptoms of dysphonia, the clinician is charged with accurate diagnosis and timely institution of appropriate therapeutic intervention. Vocal fold lesions are a common cause of hoarseness. A more thorough understanding of these benign lesions has been the goal of laryngologists and voice scientists over the last several decades, since Hirano's description of the complex layered microanatomy of the human vocal fold.

Several distinct pathologic entities are encompassed in this broad category, including laryngeal papillomatosis, intracordal cysts, sulcus vocalis, and vascular ectasia, as well as VFNs and vocal fold polyps VFPs. Each of these entities has an attendant clinical presentation; each presents diagnostic and treatment challenges. This article focuses specifically on vocal fold nodules VFNs and vocal fold polyps VFPs.

Intervention in the form of voice therapy to correct vocal use issues may be all that is required to address the vast majority of VFNs, as well as some small VFPs.

Although the surgical removal of VFNs is relatively uncommon, recommendations for such a procedure include minimal normal tissue disruption, with an endpoint of a straight medial TVF edge without divots or remaining excess tissue.

Much debate continues regarding the relative merits of cold steel versus carbon dioxide laser removal of benign laryngeal pathology. Both techniques have the known potential to cause scarring with disruption of the lamina propria (LP). Despite the advent of highmagnification operative microscopes, microlaryngeal instrumentation, and the refinement of microspot manipulators for the carbon dioxide laser, both techniques require extreme care and a skilled surgeon to avoid potentially devastating vocal complications.

\section{AIMS AND OBJECTIVE}

1. Determine age and sex wise occurrence of vocal nodules in this study population.

2. Profession wise occurrence of nodules in this study population

3. Comparison between post treatment (surgical and conservative treatment groups) voice quality of the two groups.

4. Comparison between post treatment status of nodules in both the groups.

5. Comparison between the post follow up voice quality of both the groups.

6. Comparison between the recurrence the symptoms in both the 
groups during the follow up period.

7. Correlation between duration of symptoms and nodule status in the immediate post treatment period, in both groups.

\section{MATERIALAND METHODS}

Outpatient department and Indoor wards of Department of ENT and Head Neck surgery, R. G Kar Medical College from December 2017 to December 2019

\section{H. INCLUSION CRITERIA}

1. Patient with clinically bilateral vocal nodules, as diagnosed by rigid endoscopy and FOL examination.

2. Patients of both sexes and older than the pediatric age group $(>=$ 12 years)

3. Patients without any past history of laryngeal surgery.

\section{Exclution Criteria}

1. Patients younger than 12 years age.

2. Patient with other associated laryngeal lesion/tumors

3. Patients with evidence of nasopharyngtis, oropharyngitis, hypopharyngitis.

\section{STATISTICALANALYSIS:}

For statistical analysis data were entered into a Microsoft excel spreadsheet and then analyzed by SPSS (version 25.0; SPSS Inc., Chicago, IL, USA) and GraphPad Prism version 5. Data had been summarized as mean and standard deviation for numerical variables and count and percentages for categorical variables. Two- sample ttests for a difference in mean involved independent samples or unpaired samples. Paired t-tests were a form of blocking and had greater power than unpaired tests. Unpaired proportions were compared by Chi-square test or Fischer's exact test, as appropriate. $\mathrm{p}$ - value $\leq 0.05$ was considered for statistically significant

\section{RESULT AND ANALYSIS}

Our study showed that in group-A, $6(35.3 \%)$ patients had $<30$ years of age, $8(47.1 \%)$ patients had $31-40$ years of age and $3(17.6 \%)$ patients had $41-50$ years of age. In group-B, $8(24.2 \%)$ patients had $\leq 30$ years of age, $18(54.5 \%)$ patients had $31-40$ years of age and $7(21.2 \%)$ patients had 41-50 years of age. Association of age vs. group was not statistically significant $(\mathrm{p}=0.7112)$. In group- $\mathrm{A}, 15(88.2 \%)$ patients were female and $2(11.8 \%)$ patients were male. In group-B, $19(57.6 \%)$ patients were female and $14(42.4 \%)$ patients were male. Association of sex vs. group was statistically significant $(p=0.02769)$

It was found that in group-A, $4(23.5 \%)$ patients were regressing and $13(76.5 \%)$ patients had resolve. In group-B, $4(12.1 \%)$ patients had persisting and $29(87.9 \%)$ patients were regressing. Association of post Rx VCN vs. group was statistically significant $(\mathrm{p}<0.001)$. In group-A, $16(94.1 \%)$ patients had no recurrence and $1(5.9 \%)$ patient had recurrence. In group-B, $21(63.6 \%)$ patients had no recurrence and $12(36.4 \%)$ patients had recurrence. Association of Rec Symp vs. group was statistically significant $(\mathrm{p}=0.0199)$.

We found that in group-A, 17(100.0\%) patients had resolve. In groupB, $2(6.1 \%)$ patients had increase, $4(12.1 \%)$ patients had persisting, $3(9.1 \%)$ patients had recurrent and $24(72.7 \%)$ patients had regress. Association of post F/UVCN vs. group was statistically significant $(\mathrm{p}<0.001)$. In group- $A$, the mean duration (mean \pm s.d.) of the patients was $5.9559 \pm 4.6723$.In group- $B$, the mean duration (mean \pm s.d.) of the patients was $6.8818 \pm 4.0286$.Distribution of mean duration vs. group was not statistically significant $(\mathrm{p}=0.4695)$.

\section{DISCUSSION}

We found that in group-A, 6(35.3\%) patients had $\leq 30$ years of age, $8(47.1 \%)$ patients had $31-40$ years of age and $3(17.6 \%)$ patients had $41-50$ years of age. In group-B, $8(24.2 \%)$ patients had $\leq 30$ years of age, $18(54.5 \%)$ patients had $31-40$ years of age and $7(21.2 \%)$ patients had 41-50 years of age. Association of age vs. group was not statistically significant $(\mathrm{p}=0.7112)$. In group- $\mathrm{A}, 15(88.2 \%)$ patients were female and $2(11.8 \%)$ patients were male. In group-B, $19(57.6 \%)$ patients had female and $14(42.4 \%)$ patients had male. Association of sex vs. group was statistically significant $(\mathrm{p}=0.02769)$

Béquignon $\mathbf{E}$ et al ${ }^{9}$ (2013) found that out of 90 patients (69\%) (60 women, 2 men with a mean age of 33 years) answered the questionnaire at a mean interval of 9.5 years after surgery. Absence of postoperative voice therapy was significantly associated with a higher recurrence rate $\left(\mathrm{P}^{1 / 4} / 4.02\right)(56 \%$ of recurrent dysphonia without voice therapy versus $22 \%$ with voice therapy). Postoperative voice therapy decreases the risk of recurrence.

We found that in group-A, 4(23.5\%) patients had regressing and $13(76.5 \%)$ patients had resolve. In group-B, $4(12.1 \%)$ patients had persisting and $29(87.9 \%)$ patients had regressing. Association of post Rx VCN vs. group was statistically significant $(\mathrm{p}<0.001)$.

We found that in group-A, $16(94.1 \%)$ patients had no recurrence and $1(5.9 \%)$ patient had recurrence. In group-B, $21(63.6 \%)$ patients had no recurrence and $12(36.4 \%)$ patients had recurrence. Association of Rec Symp vs. group was statistically significant $(p=0.0199)$.

We found that in group-A, 17(100.0\%) patients had resolve. In groupB, $2(6.1 \%)$ patients had increase, $4(12.1 \%)$ patients had persisting, $3(9.1 \%)$ patients had recurrent and $24(72.7 \%)$ patients had regress. Association of post F/UVCN vs. group was statistically significan $(\mathrm{p}<0.001)$

Jeong WJ et al ${ }^{10} \mathbf{( 2 0 1 4 )}$ found that time course and resolution of VF nodule of $94 \mathrm{VF}$ nodules, 43 (46\%) showed a clinically significant reduction in size, and $36(38 \%)$ resolved completely without requiring surgery. Multivariate analysis showed that VF nodule were most likely to resolve in female patients and resolved nodule, $44 \%$ and $81 \%$ were resolved at 3 months and 8 months, respectively. VF nodule may benefit from conservative management, especially female patients and those with small, recent-onset polyps. The majority of polyps that resolve do so within 8 months, which can assist clinical decision making and counseling.

Wang CT et al ${ }^{11}$ (2014) found that in vocal Nodule, the lesion reduction rate after VFSI was higher than that following VHE at 1 and 2 months $(\mathrm{P}<0.01)$. In patients with high occupational vocal demands, the lesion sizes decreased significantly at 1 and 2 months following.

Lin $\mathbf{L}$ et al ${ }^{12}$ (2014) found that the training group was additionally treated with vocal training, including relaxation training, breathing training, basic pronunciation training, chewing voice training and tone sandhi pronunciation training, and attention was paid to the training steps. Subjective and objective voice evaluations of the two groups were compared three months after the surgery and the differences between groups were statistically significant $(\mathrm{P}<0.05)$. Voice training may significantly improve the postoperative voice quality of patients with vocal cord polyps and support rehabilitation.

Pedersen $\mathrm{M}$ et al $^{13}$ (2012) found that surgical intervention for vocal cord nodules with non" surgical treatment or no treatment. No suitable trials were identified. No studies fulfilled the inclusion criteria. There is a need for high quality randomised controlled trials to evaluate the effectiveness of surgical and non surgical treatment of vocal cord nodules.

\section{CONCLUSION}

VF nodule may benefit from conservative management, especially female patients and those with small, recent-onset nodule. The majority of nodule that resolve do so within 8 months, which can assist clinical decision-making and counseling.

Voice training may significantly improve the postoperative voice quality of patients with vocal cord nodule and support rehabilitation.

Vocal fold nodule is one of the most frequent benign laryngeal lesions, influencing the quality of life of those affected by them, primarily the vocal production. Despite being a well-established therapy in conjunction with surgery, speech therapy alone may also be effective in treating these lesions.

Last, but not the least, patient compliance is extremely important for the result specially voice Quality.

Table: Association between Age in Years, Sex and Rec Symptom vs GROUP

\begin{tabular}{|c|c|c|c|c|c|c|}
\hline & & & GROUP & & & \\
\hline & & GROUP A & GROUP B & TOTAL & $\begin{array}{c}\text { Chi-square } \\
\text { value }\end{array}$ & p-value \\
\hline Age & $\leq \mathbf{3 0}$ & 6 & 8 & 14 & .6817 & 0.7112 \\
in & Row \% & 42.9 & 57.1 & 100.0 & & \\
Years & Col \% & 35.3 & 24.2 & 28.0 & & \\
\hline
\end{tabular}




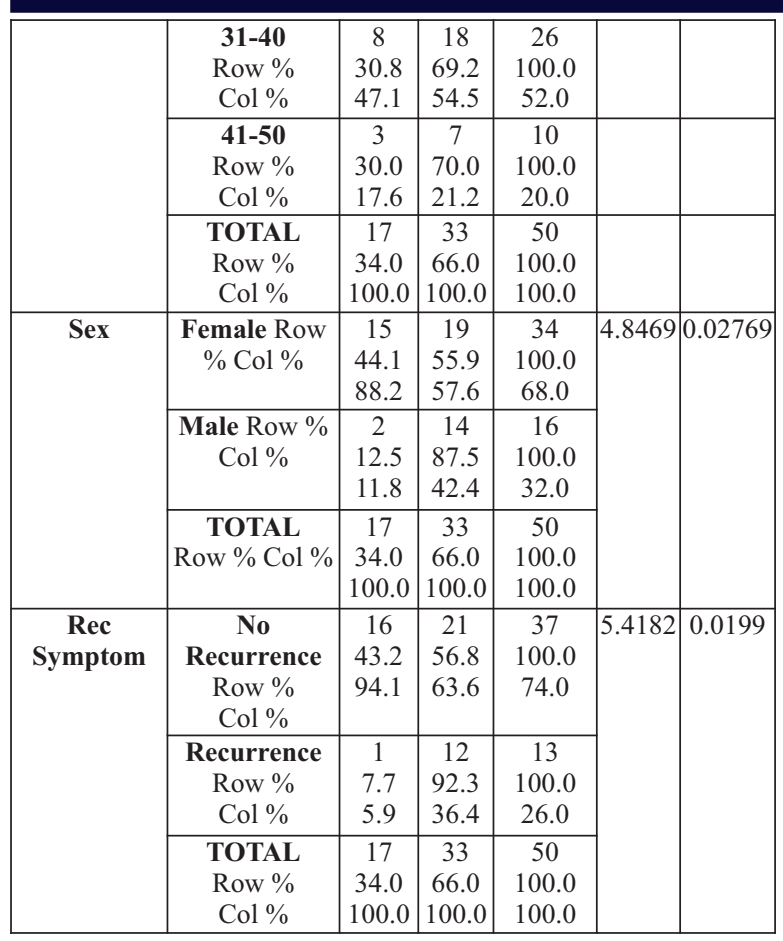

\section{REFERENCE}

Nagata K, Kurita S, Yasumoto S, Maeda T, Kawasaki H, Hirano M.Vocal fold polyps and nodules. A 10-year review of 1156 patients.Auris-Nasus- Larynx (Tokyo) 1983;Suppl 10:S27-35.Lacina (1972)

2. Lacina $\mathrm{O}$. The incidence of vocal fold nodules with singers [DasVorkommen von Stimmlippenknötchen bei den Sängern].Folia Phoniatrica1972;24:345- 54.HughMumer (1997).

3. Hugh-Munier CM, Scherer KR, Lehmann W, Scherer U. Coping strategies, personality, and voice quality in patients with vocal fold nodules and polyps. Journal of Voice 1997;11:452-61.

4. Xu JH, Ikeda Y, Komiyama S. Bio-feedback and the yawning breathpattern in voice therapy: a clinical trial. Auris-Nasus-Larynx (Tokyo)1991;18:67-77. Pedersen 1997Pedersen M. Biological development and the normal voice in puberty[thesis]. Oulu: ActaUniversitatisOuluensis, 1997:17-24.Hocever (1997); Kuhn (1998).

5. Wendler J, Seidner W. Results of surgical treatment of bones and polyps of the vocal folds in adults [[Ergebnisse operative Behandlung von Knochen und Polypen der Stimmlippen bei Erwachsenen]]. FoliaPhoniatrica1971;23:429-39.

6. El Uali Abeida M, Fernandez Liesa R, Valles Varela H, Garcia Campayo J, Rueda Gormedino P, Ortiz Garcia A. Study of the Influence of Psychological Factors in the Etiology of Vocal Nodules in Women. J Voice. 2011 Nov 14.

7. Cipriani NA, Martin DE, Corey JP, Portugal L, Caballero N, Lester R, et al. The Clinicopathologic Spectrum of Benign Mass Lesions of the Vocal Fold due to Vocal Clinicopathologic Spectrum of Benign Mass Lesi
Abuse. Int J Surg Pathol. 2011 Oct. 19(5):583-7.

8. Yamasaki R, Behlau M, Brasil Ode O, Yamashita H. MRI anatomical and morphological differences in the vocal tract between dysphonic and normal adult women. J Voice. 2011 Nov. 25(6):743-50

9. Béquignon E, Bach C, Fugain C, Guilleré L, Blumen M, Chabolle F, Wagner I. Long* term results of surgical treatment of vocal fold nodules. The Laryngoscope. 2013 Aug;123(8):1926-30

10. Jeong WJ, Lee SJ, Lee WY, Chang H, Ahn SH. Conservative management for vocal fold polyps. JAMA Otolaryngology-Head \& Neck Surgery. 2014 May 1;140(5):448-52.

11. Wang CT, Liao LJ, Lai MS, Cheng PW. Comparison of benign lesion regression following vocal fold steroid injection and vocal hygiene education. The Laryngoscope. $2014 \mathrm{Feb} ; 124(2): 510-5$.

12. Lin L, Sun N, Yang Q, Zhang Y, Shen J, Shi L, Fang Q, Sun G. Effect of voice training in the voice rehabilitation of patients with vocal cord polyps after surgery. Experimental and therapeutic medicine. 2014 Apr 1;7(4):877-80.

13. Pedersen M, McGlashan J. Surgical versus non* surgical interventions for vocal cord nodules. Cochrane Database of Systematic Reviews. 2012(6). 